\title{
ERRATUM
}

Chang Chun Kang $\cdot$ Yang Mei Ru $\cdot$ Su Ji Ying Yan Feng · Tao Ying $\cdot$ Li Xiao $\cdot$ Pu Quan

\section{A method for preserving monoclonal marker expression in bone marrow biopsies from haematological disorders using a glycol methacrylate cold-embedding technique}

Published online: 23 December 2004

(C) Springer-Verlag London Limited 2004

\section{Comp Clin Path (2004) 13:35-38}

This article was unfortunately published without Figures $1,2,3$, and 4 that are mentioned in the Results section (p. 36). These figures are now reproduced here.
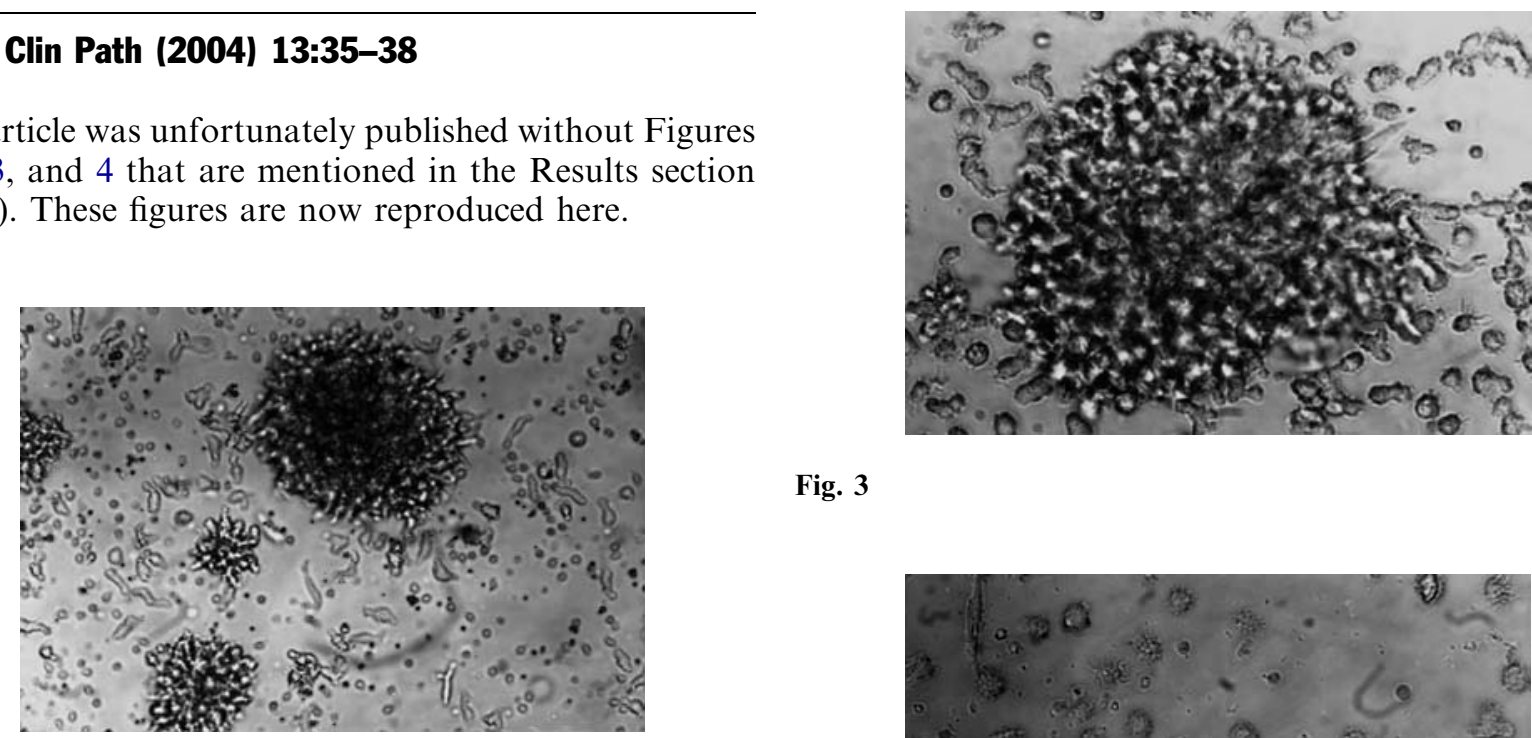

Fig. 3

Fig. 1
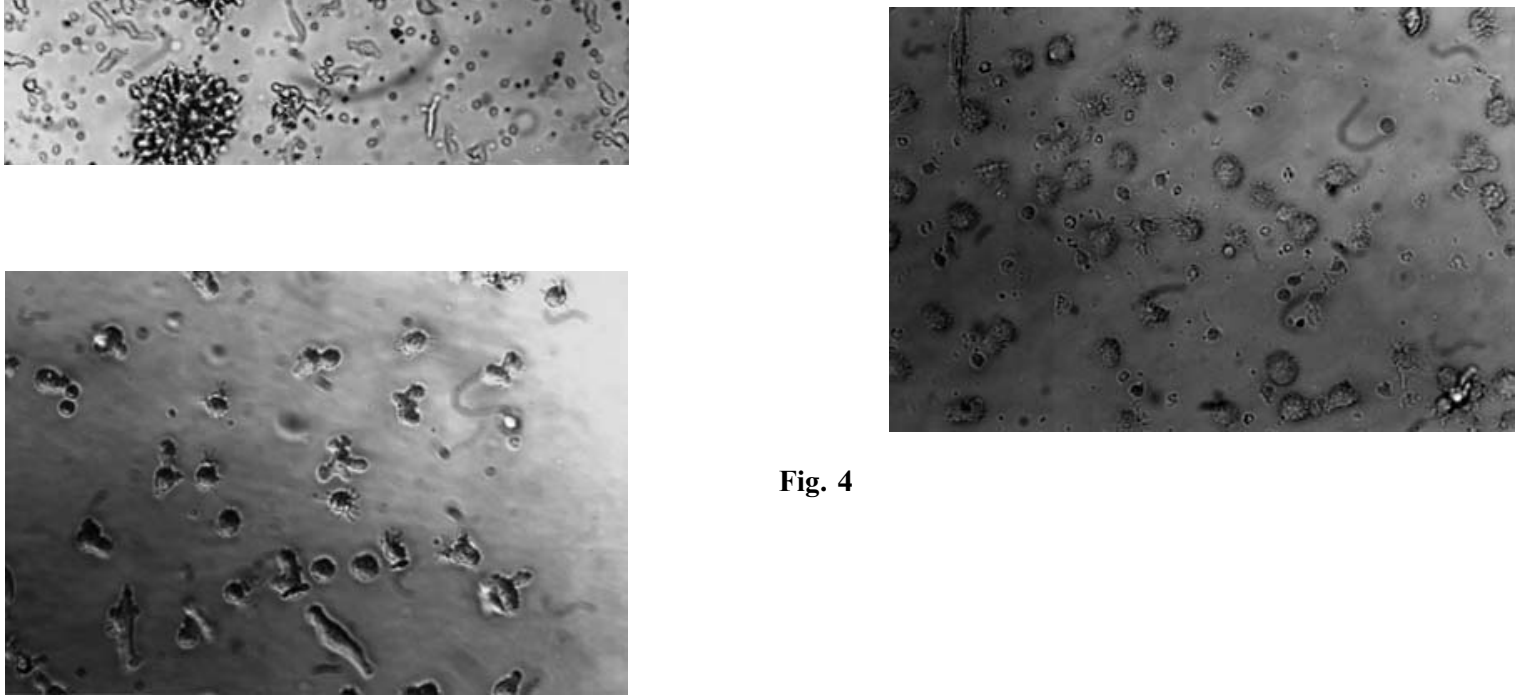

Fig. 4

Fig. 2

The online version of the original article can be found at http:// dx.doi.org/10.1007/s00580-004-0511-9

C. C. Kang $(\bowtie) \cdot$ Y. M. Ru $\cdot$ S. J. Ying $\cdot$ Y. Feng

T. Ying $\cdot$ L. Xiao $\cdot$ P. Quan

Department of Hematology, Shanghai Sixth People's Hospital,

Shanghai, 200233, China, E-mail: songluxi@ citiz.net 